\title{
Una Revisión de Literatura acerca del Arte Dramático como Terapia Alternativa para Poblaciones Vulnerables y Excluidas ${ }^{1}$
}

A Literature Review on Dramatic Art as an Alternative
Therapy for Vulnerable and Marginalized Populations

\section{José Joaquín García García*}

(iD https://orcid.org/0000-0002-5009-7942

\author{
Nubia Jeannette Parada Moreno** \\ (iD) https://orcid.org/000-0003-4313-0879 \\ Arley Fabio Ossa Montoya*** \\ (iD) https://orcid.org/0000-0002-0171-0317
}

Tipo de Artículo: Informes de Investigación y ensayos inéditos

Doi: 10.17533/udea.unipluri.20.2.018

García García, J. J., Parada Moreno, y Ossa Montoya, A. F., N. J. (2020). Una Revisión de Literatura acerca del Arte Dramático como Terapia Alternativa para Poblaciones Vulnerables y Excluidas. Uni-Pluriversidad, 20(2), e20202018. doi: 10.17533/udea. unipluri.20.2.018

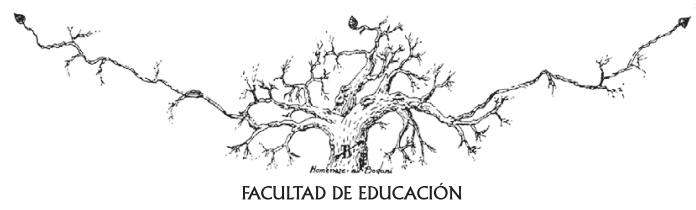

Recibido: 2020-01-21 • Aprobado: 2020-12-22

* Universidad de Antioquia, Colombia.

Email: joaquin.garcia@udea.edu.co

** Asociación Pequeño Teatro. Universidad de Antioquia, Colombia.

Email:nubia.parada@udea.edu.co

*** Universidad de Antioquia, Colombia.

Email: arley.ossa@udea.edu.co 


\title{
Resumen
}

El artículo analiza el arte dramático: talleres, juego dramático, drama creativo, dramatización, improvisación y el teatro mismo, como terapia alternativa para contrarrestar problemáticas psicosociales en sujetos vulnerables y excluidos. Para llevar a cabo este propósito, se utilizó un diseño cualitativo, a través de una perspectiva de tipo documental, que se centró en las categorías arte dramático, y poblaciones vulnerables y excluidas. Se presentan los hallazgos de las relaciones sobre estos conceptos, luego de revisar y analizar las bases de datos Apa Psyc Net, Cambrige J, DOAJ, JSTOR, SCIELO, Science Direct, EBSCO, Wilson, Web of Science, entre otras fuentes. En esta perspectiva, a partir de un trabajo llevado a cabo en un horizonte crítico-interpretativo, se revisaron las producciones realizadas por investigadores usando los instrumentos de matriz bibliográfica y matriz analítica de contenido. Como resultado, se reconoció el arte dramático como herramienta para ayudar a población vulnerable y se identificaron diferentes metodologías y resultados de las investigaciones en las que se utilizó el arte dramático para disminuir las exclusiones. Se concluye que el arte dramático, a partir de la atención al lenguaje corporal, al pensamiento, a la obra teatral, a los cambios que el sujeto tiene en la representación de personajes, entre otros, acrecienta el ingenio y la comunicación, y posibilita un desarrollo estético y plástico. Este tipo de modificaciones aportan a mejorar el nivel biopsicosocial de la población vulnerable y excluida, a reconfigurar su personalidad e historias personales, desarrollar habilidades sociales, mejorar su comunicación, darles herramientas para resolver problemas, a gestionar sus emociones y a potenciar su autoestima; estas capacidades y desarrollos humanos, son sustanciales para contrarrestar las problemáticas psicosociales que acarrean su situación de fragilidad y marginación.

Palabras clave: arte dramático, terapia alternativa, población vulnerable, población excluida.

\begin{abstract}
The article analyzes dramatic art as an alternative therapy to counteract psychosocial problems in vulnerable and excluded subjects. Dramatic art includes workshops, dramatic play, creative drama, dramatization, improvisation, and the theater. To this purpose, a qualitative design was used, through a documentary perspective, which focused on two categories: dramatic art, and vulnerable and excluded populations. The findings on these concepts are presented here, after the review and analysis of the Apa Psyc Net, Cambrige J, DOAJ, JSTOR, SCIELO, Science Direct, EBSCO, Wilson, Web of Science, among other sources. In this perspective, based on a work carried out in a critical-interpretative horizon, studies made by researchers were reviewed, using a bibliographic matrix and analytical matrix of content
\end{abstract}


as instruments. As a result, dramatic art was recognized as a tool to help vulnerable populations; and different methodologies and research results, where dramatic art was used to reduce exclusions, were also identified. It is concluded that dramatic art, based on attention to body language, thought, theatrical work, changes that the subject has in the performance, among others, increases ingenuity and communication, and enables aesthetic and plastic development. This type of modifications contributes to improve the biopsychosocial level of vulnerable and marginalized population, to rebuild their personality and personal stories, to develop social skills, to improve their communication, to provide tools to solve problems, to manage emotions, and to improve their self-esteem; these are substantial capacities and human developments to counteract the psychosocial problems that derive from their situation of fragility and exclusion.

Keywords: dramatic art, alternative therapy, vulnerable population, marginalized population. 


\section{INTRODUCCIÓN}

En el mundo contemporáneo, el 70\% de los seres humanos está excluido de los beneficios del desarrollo humano (Gasparini, Bracco, Galeano y Pistorio, 2018). Esta exclusión se configura debido a los efectos de un desarrollo economicista, anclado en la creación de factores materiales e institucionales requeridos por la civilización industrial. Se entiende como el nulo o escaso acceso a bienes socioculturales y económicos, a causa de la falta de recursos materiales, a la carencia o insuficiencia de capacidades o debido a limitaciones para el ejercicio de los derechos como ciudadanos. Dichas condiciones son propias, en su mayoría, de personas pobres, de mujeres en condiciones de vulnerabilidad, de poblaciones en encierro carcelario u hospitalario, de inmigrantes y de personas en condición de discapacidad. Esta población excluida por su condición puede adquirir la connotación de ser al mismo tiempo vulnerable, es decir, estar potencialmente expuesta a la falta de garantías para el disfrute de sus derechos fundamentales. Ambos tipos de poblaciones, la excluida y la vulnerable, deben ser reconocidas con el objeto de buscar alternativas y soluciones a sus problemáticas.
Ante la marginalidad social que se genera por un desarrollo enfocado al crecimiento económico y no al desarrollo humano, el arte dramático puede representar una alternativa para la inclusión social, resolviendo dificultades como su baja autoestima, habilidades sociales deficientes, capacidades comunicativas y de resolución de problemas poco desarrolladas y una gestión inadecuada de las emociones. En consecuencia, en primer lugar, se expondrán referentes teóricos acerca de cómo se pueden contrarrestar las anteriores problemáticas a través del teatro. En segundo lugar, se presentarán los métodos de investigación y las formas de recolección de información que se usaron para indagar la relación entre el uso del arte dramático y la disminución de las exclusiones y vulnerabilidades ancladas a dificultades socioculturales en grupos desfavorecidos. En tercer lugar, se evidenciarán los resultados de investigaciones que han usado el teatro para proponer soluciones a dificultades que afec$\tan$ a los excluidos. Finalmente, se procederá a discutir dichos resultados $\mathrm{y}$ a presentar algunas conclusiones sobre la relevancia del arte dramático para poblaciones vulnerables y excluidas.

\section{EL ARTE DRAMÁTICO PARA AYUdAR A SUJETOS EXCLUIDOS}

Los individuos que no alcanzan las metas esperadas o no logran satisfacer las expectativas son valorados de forma negativa por sujetos y grupos, siendo por esta calificación excluidos. Esto ocurre porque las comunidades interpretan las diferencias como deficiencias y tratan a las personas diferentes como deficientes, excluyéndolas de las actividades normales. Dicha exclusión les genera una desacreditación social, una débil potencialización, sentimientos de inferioridad, impotencia y dependencia; aspectos que en su conjunto menguan su autoestima (Pereira, 1999).

Situaciones como las anteriores se presentan porque los grupos en general tratan de protegerse frente a lo que ellos desconocen, porque lo ven como una amenaza para los va- 
lores y criterios establecidos de normalidad. Además, dicha exclusión se basa en juicios acerca de los diferentes, casi siempre realizados sólo sobre percepciones sensoriales. Así, para los "normales", los "distintos" son una amenaza que se debe atacar, agredir, rechazar, abandonar, alejar, negar, sobreproteger, disciplinar o normalizar (Foucault, 2001: Cordeiro, Scoponi, Ferreira y Vieira, 2007).

A través del arte dramático, el individuo "diferente" que es excluido puede expresar- se y socializar su ser singular; elaborar sus emociones, sentimientos y deseos; mejorar sus habilidades e insertarse en la sociedad ya que, por estas vías, disminuye su vulnerabilidad a diversos agentes que le generan estrés como producto de estereotipos y prejuicios (Fischer, 1982). Esto hace que aquellos considerados diferentes puedan participar de forma cada vez más activa y contribuir a la sociedad, expresándose y ejerciendo su ciudadanía (Cordeiro et al., 2007).

\section{SUJETOS QUE PUEDEN BENEFICIARSE PSICOLÓGICAMENTE CON EL ARTE DRAMÁTICO}

El arte dramático es un dispositivo de constitución de subjetividades singulares, no marginales y excluidas, que tensa con los dispositivos gestados al amparo del paradigma del desarrollo economicista, emergente a mediados del siglo XX y con aquellos impulsados a la sombra de las dinámicas neoliberales nacientes en 1982. Desde dichos dispositivos se han impulsado ordenamientos y funcionamientos injustos, insolidarios e inequitativos, que han creado las condiciones de existencia para la configuración de marginamientos de variados grupos poblacionales.

En primer lugar, encontramos el grupo de los jóvenes con problemas comportamentales, que tienen dificultades para tomar decisiones, comunicarse asertivamente, afrontar situaciones y establecer relaciones inter e intrapersonales, a causa de su interacción con contextos familiares, sociales y culturales, en los que prima una educación instrumental y cosificadora, como producto de formas de vida creadas en un contexto de la civilización industrial. Dichas condiciones dificultan la convivencia de estos jóvenes, les hace rebeldes, desconfiados, inexpresivos, inseguros, aislados, sin autocontrol, desinteresados, pesimistas, con un auto concepto negativo y baja auto estima; características que, por lo general, provocan un bajo rendimiento escolar (Crimmens, 2006).

Estos rasgos psicológicos se expresan en los jóvenes con síntomas como ansiedad, malestar emocional, desajuste psicológico y social, depresión, desesperanza, tendencias suicidas, agresividad, nerviosismo, timidez, tensión, indecisión para presentar sus ideas, introversión, pasividad, inhibición, inseguridad, tartamudez, victimización, impotencia, incapacidad de afirmación, dependencia social, baja creatividad y poca competencia académica $\mathrm{y} / \mathrm{o}$ profesional (Beauregard, Bouffard y Duclos, 2005). Además, presentan muy baja autonomía y altos niveles de frustración, por tanto, se estancan en su evolución psicosocial, al ser incapaces de aceptar las críticas y considerarse personas no exitosas o líderes, y sentirse más bien en estado de indefensión o constantemente amenazados por la sociedad. Estas dificulta- 
des son afrontadas por ellos en un contexto de desarrollo en el que las dinámicas educativas están ancladas de forma hegemónica en los imperativos económicos y del mercado. Es importante aclarar que la mayoría de estos jóvenes vive en la periferia de las grandes ciudades, es decir, en lugares con presencia de marginalidad y vulnerabilidad económica, social y cultural (Rocha, Levitan, Piana, Velarde \& Vieira, 2011).

Al mismo tiempo, estos jóvenes son producto de una cultura individualista y de diversidad de prácticas híbridas que fluyen en todos los niveles de los dispositivos socioeconómicos. Dichas prácticas incluyen juegos que no requieren de compañeros $\mathrm{y}$ valores que no van más allá del bienestar personal, en los que se desconoce el compromiso social (Navarro, 2006), y las dimensiones comunitarias e históricas. Además de los problemas comportamentales, dichas dificultades están acompañadas, la mayoría de las veces, de patologías psicológicas como anorexia, bulimia, tendencias suicidas y consumo de drogas (Brooke, 2009). Por tanto, el arte dramático podría impulsar el uso de un lenguaje permeado por un mundo sensible, en el que los jóvenes aprendan sobre su propio universo, a partir del despliegue de sentimientos placenteros y desagradables, atravesados en las representaciones por la creatividad, la ética, la autonomía, la liberación, la subjetivación, los afectos, las emociones, la imaginación, la intuición, la reflexión, la razón, en síntesis, por la atención de sí (Côrtes, 2014).

En segundo lugar, se encuentra el grupo de las mujeres en situación de riesgo, entre ellas, jóvenes prostitutas, víctimas de explotación y/o abuso sexual (Silverman \& Marvasti, 2008), madres que han tenido que dar a sus hijos en adopción por violencia intra- familiar o drogadicción, mujeres sin techo o con problemas de salud mental, así como las que sufren discriminación por pertenecer a una minoría sexual. Es decir, este grupo incluye a las poblaciones femeninas que requieren reconocer sus propias historias para reescribirlas y poder seguir adelante (González, 2015). Este objetivo podría lograrse gracias a la percepción razonada, la multiplicidad de ejercicios estéticos (Winston, 2005), la reavivación del ser, (Motos, 2010), la fluidez y la transformación de prácticas corporales, propuestas en las diversas expresiones teatrales.

En tercer lugar, el arte dramático puede ser usado para potenciar la comunicación interpersonal y la expresividad de poblaciones adultas que presentan dificultades sociales e intelectuales y que residen en centros de internamiento como hospitales y refugios para gente sin techo (Mesquita, 2012). Estos adultos tienen retardo en el habla y en la capacidad de comprensión de mensajes; se interesan sólo por efectos prácticos y beneficios tangibles, dejando a un lado las relaciones interpersonales y el desarrollo espiritual y; son egocéntricos, además de hostiles y poco sociales (Foloştină, Tudorache, Michel, Erzsébet \& Duţă, 2015).

Otra población en riesgo que se puede intervenir para acrecentar el control emocional a partir del uso del arte, específicamente del teatro, es la conformada por niños y adolescentes inmigrantes. Esta población presenta una identidad híbrida (compartida entre su lugar de origen y el sitio donde están ahora), y sufre una brecha psicológica entre el pasado que han vivido y el presente que vive, el hogar con sus costumbres de origen y la escuela con las nuevas costumbres. Además, estos niños y adolescentes al haber pasado en sus lugares de origen por 
experiencias traumáticas (agravio, discriminación, exclusión) y de duelo (pérdida de esperanza, abandono, separación), sufren de angustia y dificultades emocionales, conductuales y/o de aprendizaje (Rousseau et al., 2014). El uso del teatro puede ayudar a solventar estas situaciones, al impulsar una metodología activa, en la que los procesos de enseñanza y aprendizaje se relacionan con el mundo perceptivo y emocional, y se prioriza al ser humano, reivindicándose su dignidad a partir del reconocimiento de un contexto hostil y mercantilista.

Finalmente, el arte dramático también ha sido usado para mejorar las habilidades emocionales y cognitivas de poblaciones consideradas "normales", como las constituidas por los estudiantes matriculados en instituciones de educación formal. En este caso, el arte dramático ha sido empleado para que los estudiantes creen realidades alternas, soluciones y visiones ficticias pero posibles en el futuro. El fin es prepararlos para que creen su propio porvenir y no se queden simplemente en adaptarse al futuro que otros han creado para ellos. Así, la educación para el futuro ha sido reemplazada por los futuros en educación (Lehtonen, 2012).

En este sentido, el uso del arte dramático es importante porque los jóvenes enfrentan hoy problemáticas inmensamente graves, como el cambio climático y el caos mundial, provocado por la escalada de gobiernos de corte nacionalista, con políticas de carácter neoliberal, que generan impactos negativos para el medio ambiente y presentan deterioro en las condiciones de vida en diferentes grupos sociales. Las intervenciones basadas en el arte dramático incrementan la consciencia de futuro en los sujetos, quienes crean imágenes con las que pueden predecir el porvenir efectivo de la especie humana (Wayman, 2009). Así, el uso del arte dramático en la formación de los jóvenes produce empoderamiento para pensar en reconstruir sus propias culturas.

\section{El ARTE dRAMÁtico PARA RECONSTRUIR LA PERSONALIdAd Y LAS HISTORIAS PERSONALES EN SUJETOS VULNERABLES}

El arte dramático hace posibles variaciones profundas en los modos de vivir y concebir la realidad (Rocha et al., 2011) de las poblaciones vulnerables. Además, el uso del teatro ejerce en este tipo de poblaciones una gran influencia respecto a los cambios que se producen en la imagen de sí mismas, de los otros y de la realidad. El teatro lo logra al permitir reflexionar sobre la existencia y construir nuevas imágenes, tanto con el cuerpo como con las palabras. Así, la experiencia estética teatral, posibilita una actitud mucho más sensible para las vivencias posteriores y deja profundas huellas en el comportamiento humano.
En el teatro, las imágenes construidas se convierten en realidades posibles y propias, fruto de un proceso de creación relacionado con las experiencias, la historia y el contexto de los creadores (Zanella, 2007). Esto sucede porque las palabras surgen de la interacción de los sujetos y de los sentidos que involucran, e incluyen relaciones de alteridad (Bakhtin, 1990) con interpenetración, fusión, y reflexión, haciendo la experiencia teatral simultáneamente polisémica y dialógica. En consecuencia, en el teatro se produce la emergencia de una unidad de comunicación discursiva nueva y real, muy relevante para las personas con vulnerabilidad. 
En el teatro se des-naturalizarían imágenes anquilosadas de sí mismo y de la realidad, imágenes que han sido construidas usando estigmatizaciones y preconceptos creados por los medios masivos de comunicación, para crear otras más adecuadas y recrear los sentidos que la juventud da a los procesos. Es decir, el teatro posibilitaría interiorizar puntos de vista alternativos. Dichos sentidos e imágenes son objetivados en la expresión corporal y en las posibilidades performativas de apropiarse de nuevos perfiles y nuevas formas de dotar de significado a la realidad y de visionar el futuro. De esta manera, los sujetos vulnerables construyen a través de las prácticas teatrales nuevos valores éticos, estéticos y políticos, nuevas identidades como sujetos y ciudadanos y nuevos porvenires anclados a una vida activa y un pensamiento afirmativo, a través de la razón, el cuerpo y la afectividad. De esta forma, sus identidades, distanciadas de la realidad vivida, redimensionan la existencia, la imagen de sí mismo y la idiosincrasia, en función de la transformación de las voces sociales, los modelos de pensamiento colectivo y la creación de un nuevo sujeto. Dicho nuevo sujeto tendría la capacidad de inventar para aparecer y afirmarse a sí mismo a partir del desplazamiento y anulación de aquello que le hacía vulnerable y le impedía improvisar, crear, sentir, moverse, ejercitarse; aquello que le imposibilitaba experimentar nuevos lenguajes para poder crear y vivir otro tipo de existencia.

Las anteriores consideraciones coinciden con el reconocimiento del arte dramático como un arte esencial para el desarrollo humano (Organización de Naciones Unidas [ONU], 2007). Esto es así porque el teatro permite a la población excluida formarse como actores expresivos, libres, auténticos, equilibrados, humanos, independientes, socialmente hábiles, con alta autoestima, tolerantes, capaces de reconocer y disfrutar la lúdica, y vivenciar experiencias con significado, autoconocimiento y saber social. Dichos sujetos potencian su capacidad para expresarse de forma libre y para priorizar su vocación humana.

Es decir, para el sujeto vulnerable hacer teatro es un proceso liberador, expresivo y equilibrador de las emociones, los sentimientos, las percepciones y las sensaciones a través del acto creativo. En esta misma perspectiva, algunos autores han encontrado que el uso del drama creativo con la población diferente posibilita un desarrollo emocional adecuado, formación en la cooperación social, aumento en la seguridad interna de los sujetos, mayores posibilidades para lograr su expresión creativa y para generar pensamiento crítico, mayor concentración, conciencia sensorial, equilibrio físico y sensibilidad estética (Massey \& Koziol, 1978).

\section{EL TEATRO Y EL DESARROLLO DE HABILIDADES SOCIALES EN POBLACIÓN VULNERABLE}

En el teatro se desarrolla la empatía y se sitúa a los actores con diferentes tipos de vulnerabilidad en la situación de otro personaje. Además, el teatro requiere que se comprenda a los compañeros de faena, en un clima de confianza, trabajo colectivo, cooperación, colaboración, participación, capacidad de escucha, disposición de negociación (Rich, 1995; Lillard, Pinkham \& Smith, 2011), búsqueda de acuerdos para la 
construcción de respuestas grupales a las circunstancias (Stagnitti \& Unsworth, 2000), y constante auto/revisión de las acciones propias y de las de los demás. Estas vivencias permiten superar los miedos y explorar emociones, sentimientos y comportamientos en los excluidos. Por ello, el teatro favorece la inteligencia interpersonal e intrapersonal en este tipo de población (Gardner, 1999; Dickinson \& Neelands, 2006).

También es necesario decir que a través del teatro se puede comprender mejor cómo se comportan e interactúan las personas y qué las motiva en el marco de su cultura y en un momento histórico determinado. Esto sucede porque hace que los actores y espectadores sitúen las cosas en otros contextos, elaborando conexiones e implicaciones. Sobre este aspecto, el teatro puede servir para mejorar la condición emocional de los sujetos vulnerables porque permite a los sujetos, entre otras cosas, liberar tensiones contenidas de carácter emocional y sentimental, ser extrovertidos y abiertos, mejorar la expresión corporal, auto/descubrir valías y capacidades y reconocer programaciones mentales perjudiciales (Navarro, 2006). Así mismo, el arte dramático permite afianzar la identidad y la elección sexual, mejorar la autoimagen, la auto-valía y el auto concepto a través del reconocimiento social, de la ejercitación del pensamiento analítico-crítico e hipotético, y la elección de comportamientos socialmente respetables. Estos aportes del teatro son fundamentales para la conformación de una conciencia de sí, para poder problematizar o confrontar fragmentos de los despliegues ausentes que han tejido al sujeto marginal en su historicidad. Así, estos fragmentos emergen en el teatro por la vía de sus valiosas y variadas experiencias, gracias a las cuales se facilita el encuentro con el pasado vivido en condiciones de vulnerabilidad. Este encuentro es posible, en tanto en las practicas teatrales se pueden avivar o desencadenar historias y memorias no recordadas, aspectos que permiten la transformación del entendimiento sobre sí mismo (Butterwick \& Selman, 2012). El teatro, como instrumento de memoria, nos llama la atención sobre el sentido del regreso y sobre la extraña práctica de revisitar. En la perspectiva anterior, el drama se convierte en un extraño lente que permite ir al pasado y favorecer la afirmación de la conciencia y, por esta vía, la redefinición de la identidad.

\section{EL TEATRO PARA MEJORAR LA COMUNICACIÓN Y LA RESOLUCióN DE PROBLEMAS EN LOS VULNERABLES}

El teatro puede mejorar en la población frágil las capacidades de expresión verbal y no verbal, así como la competencia comunicativa. Esta competencia se define como la habilidad para usar relaciones y dependencias en favor de aumentar el impacto y la magnitud de lo que se dice o se trata de comunicar, es decir, su eficacia comunicacional. De igual manera, el arte dramático estimula el habla y la expresión, exige dicción fluida, pronunciación clara y proyección de la voz, todo anclado a la expresión de las propias emociones. E teatro lo logra porque posibilita la vivencia de experiencias propias de la vida real, sin el riesgo asociado a aquel tipo de prácticas que representan peligro, como adicciones, maldad, etcétera (Schechner, 1985); son vivencias que en escena pueden ser placenteras, dinámicas, emocionantes, conscientes y contextualizadas. 
El teatro también permite a los sujetos con vulnerabilidad relacionarse con experiencias vividas y enfrentarse a situaciones nuevas, con la posibilidad de modificarlas; facilita resolver conflictos e integrar el juicio crítico y los valores. Como se dijo antes, esto contribuye a la construcción de una nueva identidad, en la que exploramos quiénes somos y revelamos qué podemos llegar a ser. Así mismo, al ser el teatro un proceso creativo del que hace parte la imaginación, la experiencia dramática anima a "decidir ser creativos" (Grimson, 2014; Navarro, 2005), mejora el pensamiento divergente, la fluidez de ideas y la flexibilidad (Dansky, 1980). Además, el teatro puede influenciar positivamente la originalidad, ya que puede tener la capacidad para dejar finales abiertos, lo que aumenta la tolerancia a la incertidumbre y la curiosidad, y contribuye a la dinámica social contemporánea en la que se necesita asumir riesgos (Motos y Navarro, 2003).

Por otra parte, el teatro permite colaborar para compartir tareas y jugar diferentes roles en los que los sujetos participan y resuelven conflictos, con cierta libertad y protagonismo para tomar decisiones. Así mismo, ofrece la oportunidad para reconocerse a sí mismo, adaptarse, interactuar y reconstruir simultáneamente las formas de ser y de pensar (Cojocariu \& Butnaru, 2014; Navarro, 2002).

\section{EL ARTE DRAMÁTICO PARA EXPRESAR Y GESTIONAR EMOCIONES CON POBLACIÓN VULNERABLE}

Las emociones son estados complejos y respuestas del organismo con estados fisiológicos involuntarios: tono muscular, respiración, presión sanguínea, cambios en la actividad del sistema nervioso central; reacciones conscientes e inconscientes; y conductas como expresiones faciales, movimientos corporales, tono de voz, volumen y ritmo (Parada, 2013). La emoción organiza los deseos que, al manifestarse como sentimientos, son la expresión de la identidad y de la capacidad para comunicarse. La expresión e inhibición de estas emociones son básicas en la salud psicológica y física. A través de ellas se expresa la autovalía y la identidad, y la comprensión de las emociones básicas de amor, odio, placer, dolor, miedo, ira y deseo, las cuales generan empatía, felicidad o insatisfacción (Karakelle, 2009; Alcántara, 2006).

Las emociones se manifiestan en el teatro al hacer uso de las palabras y al em- plear el lenguaje para-verbal que incluye elementos como tono, ritmo, velocidad, articulación y resonancia. Dichos elementos son expresados a través de diversas formas como el grito, el llanto, la risa, el bostezo o el suspiro. Además, la manifestación de las emociones usa los movimientos del cuerpo y de la cara como espejo del mundo interno e indican un desplazamiento afectivo y los estados emotivos: alegría, miedo, ira, tristeza, etc. (González, 2015). Estos desplazamientos emocionales con valor simbólico expresados en términos de movimiento, también son llamados kinemas. Chejov (1999) añade a estos movimientos la postura corporal que es una expresión de la tensión o el relajamiento y del estado emocional general del sujeto.

Precisamente la posibilidad de liberar y de gestionar las emociones es lo que hace que el arte dramático pueda generar en el sujeto vulnerable la denominada catarsis 
(purga o purificación). Ello ocurre cuando, por momentos, como espectadores nos relacionamos con un acto dramático en el que se muestran realidades sociales o experiencias vividas que, siendo representadas por un sujeto en el marco de un contexto reconocido, nos permiten evocar episodios de nuestra vida vulnerable pasada o presente. De este modo, se desencadena una catarsis que releva y alivia temores individuales o colectivos (Datoo, 2011). Para Tadeo (2012), estas prácticas revelan un laboratorio a través del cual es posible establecer relaciones entre lo dramático y la memoria. En ellas, el sujeto frágil se libera también de sus pasiones, lo que permite el alivio de sus tensiones emocionales. Para Aristóteles, la catarsis implica eliminar la tendencia a violar la ley; para Boal, permite reencontrar el equilibrio interno, deshaciéndose de aquello que lo perturba y; para Moreno, esta liberación es la auto-representación que permite sacar desde dentro lo que nos hace daño (Navarro, 2006, 2007).

\section{MÉTOdOS DEL ARTE DRAMÁTICO USADOS CON POBLACIONES VULNERABLES}

El uso del arte dramático para ayudar a diferentes poblaciones de excluidos ha implicado a una gran variedad de métodos. Entre los más utilizados se encuentran los talleres para el desarrollo de la autoestima que se basan en el juego dramático, el drama creativo, la dramatización, la improvisación y la conformación de grupos de teatro.

\section{Talleres basados en el juego dramático para el desarrollo de la autoestima en población vulnerable y excluida}

Los talleres para mejorar la autoestima basados en el juego dramático incluyen fases previas de sensibilización y diagnóstico y una fase de diseño y aplicación. Estos talleres de factible desarrollo con personas vulnerables y excluidas implican una variedad de juegos dramáticos por subgrupos con objetivos como sensibilización, desinhibición, desbloqueo, construcción de vínculos y confianza, exploración corporal del ritmo y del espacio, potenciación de actitudes, improvisación y asunción de roles (“como si" en situación), activación de la cooperación y la asociatividad e imitación de modelos (Wyver \& Spence, 1999). Además de los juegos teatrales, se ha propuesto otros juegos como los de canto, en los que se toca lo nombrado, de lucha con espadas y de imitación de seres imaginarios o animales, junto con la invención de historias sonoras y animadas (Foloştină et al., 2015)

En muchos casos, estos talleres son operados por compañías profesionales, como es el caso de Theatre Without Borders que se centra en procesos de paz, Impact Arts que pretende mejorar la calidad de vida de los sujetos y Open Clasp Theatre que trabaja en la difusión de los Derechos Humanos en Inglaterra (González, 2015). En otras ocasiones, dichos talleres son realizados por docentes o por directores de teatro.

Los talleres que incorporan el juego dramático aumentan la auto consciencia, la relajación y la responsabilidad de los sujetos para debilitar así su situación de exclusión. También se usan otras técnicas como la del mimo, la musicoterapia, el movimiento corporal grueso y fino, la estimulación senso- 
rial (texturas, sonido, gusto, olfato y vista), el ejercicio rítmico y de danza, la construcción y uso de máscaras, la representación de rituales, la narración de historias terapéuticas, el análisis de metáforas, ejercicios de rapidez física y mental, y los títeres. Estos ejercicios han servido para activar el inconsciente en adultos internados en instituciones y para atender a otras poblaciones con problemas de marginación y en condición de discapacidad intelectual (Foloştină et al., 2015; Crimmens, 2006).

\section{El drama creativo en procesos de exclusión}

En el drama creativo, luego de que los sujetos identifican sus fortalezas y debilidades, improvisan de forma personal y colectiva -crean- y experimentan -ejecutan- vivencias lúdicas análogas a la vida y sus problemas. Estas experiencias implican cercanía física, esfuerzo grupal, deslocalización de los modos de ser y de estar -acción-, investigación y observación sobre el tema problema que se esté trabajando de forma cooperada.

En el drama creativo se hace necesaria una selección y estabilización de la creación para construir una dramaturgia que pueda ensayarse y ejecutarse ante un público. Dicha construcción se hace con base en la verbalización y expresión de lo sentido, la reflexión, la retroalimentación y el análisis del proceso grupal en aspectos como liderazgo, comunicación, solución de conflictos, etc. Todo ello se realiza en el marco de técnicas como las del Teatro del Oprimido, con el fin de extraer ideas durante y al final de la obra en función de conseguir cambiar la realidad de los excluidos, acción que se realiza en conjunción con la comunidad. Aquí, la comunidad se transforma de espectadora en protagonista de la acción dramática, al deliberar sobre las condiciones de opresión y al establecer acciones de liberación, así, se convierte en especta-actora (Boal, 2009; Navarro, 2006; Motos, 1995; Koudela, 1992; Rocha et al., 2011). Las sesiones de drama creativo pueden ser grabadas, lo que permite mayor acompañamiento al grupo y un incremento de su concienciación en relación con las fortalezas, limitaciones, oportunidades y retos que se presentan (Beare \& Belliveau, 2008; Lillard et al., 2012; Guner \& Guner, 2012).

En relación con las personas que son rechazadas, también se ha propuesto la realización de obras de teatro definidas de forma colegiada. En ese caso, se discute el significado del teatro, el diseño de escenarios, los pasos del montaje, se realiza el casting, se estudian y comprenden los personajes y los textos de forma simultánea con la ejecución de los distintos roles que implica el montaje teatral. Finalmente, se presenta y evalúa la obra para terminar con la construcción de una memoria en función de la potenciación del colectivo (Cojocariu \& Butnaru, 2014).

\section{Dramatización e improvisación con inmigrantes y refugiados}

La improvisación y la dramatización se usan en programas de prevención para niños y adolescentes que son inmigrantes y refugiados, con el objeto de ayudarles a asimilar su experiencia de transición y a transformar sus vivencias adversas en oportunidades para aprender. Los ejercicios, juegos, improvisaciones y dramatizaciones que hacen parte de los programas se centran en la escucha, la confianza y la expresión no verbal; ayudan a conocerse, fomentar el humor $y$ desarrollar la imaginación. 
Estas experiencias se llevan a cabo en un ambiente respetuoso y tolerante de las diferencias, en el que se desarrolla solidaridad grupal. Las improvisaciones hacen uso de métodos teatrales como esculturas fluidas y situaciones ambivalentes, y son inspiradas en historias de los niños y los jóvenes. Estas historias son exploradas en profundidad para ser dramatizadas. Las dramatizaciones tratan temas como pertenencia, exclusión, aprendizaje, familia, amistad, transición de una cultura a otra, cambios de la niñez a la adolescencia y de la adolescencia a la juventud. Estos escenarios que se construyen de forma colectiva mejoran el empoderamiento de los sujetos.

En acciones como las descritas se ayuda a la construcción de significado de las historias personales, a resolver problemas de los procesos de duelo relacionados con la inmigración y el fracaso académico, a cimentar la identidad y a mejorar la visión sobre las diferencias, para desarrollar estrategias de adaptación que disminuyan la marginación (Rousseau et al., 2014).

\section{Conformación de grupos de teatro para población en condición de discapacidad}

La conformación de grupos de teatro con actores que tienen condición de discapacidad sirve para promover el contacto entre ellos, mejorar la calidad de información acerca de temas que les interesan (sexualidad, prejuicio, afectividad, noviazgo, matrimonio, diferencia entre fantasía y realidad); y para sensibilizar a las audiencias acerca de las personas con discapacidades y sobre sus posibilidades para insertarse en la sociedad. Los actores exponen en sus representaciones la consciencia de sus condiciones y muestran sus vivencias al soportar prejuicios (Prioli, Souza, Leme \& Mugnai, 2007).

\section{MÉTODOS DE INVESTIGACIÓN Y FORMAS DE RECOLECCIÓN DE INFORMACIÓN}

Las investigaciones referidas al uso del teatro para ayudar a disminuir las exclusiones en grupos desfavorecidos usan diferentes métodos como la investigación acción (Kemmis, 2007; Costley, Elliot \& Gibbs, 2010), la autoetnografía, el autoestudio, la práctica reflexiva, la observación y la investigación para formar una comunidad de aprendizaje (Muncey, 2010).

En estas pesquisas se han usado test estandarizados como la Escala de Autoestima de Rosenberg, test de inteligencia como el de matrices progresivas de Raven y el Stanford-Binet, test sobre capacidades lingüísticas como el Peabody de gráficos y vocabulario (PPVT), correlacionados los tres (Sattler,
1992), y la escala de inteligencia preescolar y primaria de Wechsler (WPPSI). De Igual manera, se han empleado técnicas de carácter cualitativo como la observación simple de la autoestima y la observación participativa a través del juego dramático. También se utilizaron rúbricas para evaluar el desempeño del grupo; encuestas semiestructuradas al público y a grupos de estudiantes ejecutantes, con preguntas y respuestas abiertas y cerradas sobre la eficacia de la intervención y la descripción de la experiencia; entrevistas antes y después de la intervención; notas de campo y video grabación.

La mayoría de los datos surgidos de los instrumentos cualitativos fueron mapea- 
dos para determinar discursos y categorías emergentes (Guner \& Guner, 2012; Rocha et al., 2011; Lehtonen, 2012).

En esta tendencia también se utilizaron cuestionarios de fortalezas y dificultades con escala Likert, para medir el deterioro emocional y conductual en niños y adolescentes que tenían la condición de inmigrantes y/o refugiados. La medición de hacía en términos de cronicidad, angustia, deterioro social y sentimiento de ser una carga para otros (Rousseau et al., 2014).

\section{Algunos resultados en usos del arte dramático para procesos EDUCATIVOS CON PERSONAS VULNERABLES Y EXCLUIDAS}

La intervención de grupos vulnerables con actividades de juego dramático logró elevar sus niveles de autoestima y mejoró su autoafirmación y autoconcepto al permitir mayor autocontrol, aceptación e introspección (Baracaldo y Niño, 2015). Además, se evidenció un mejoramiento en la capacidad para resolver problemas (Vandenberg, 1980) y en las habilidades comunicativas y sociales (Copple \& Bredekamp, 2009). Así mismo, el uso del juego dramático presentó correlaciones positivas con los resultados de los test de inteligencia y de los que miden capacidades narrativas, orales y de comprensión, además de capacidades básicas de atención y memoria (Blair \& Peters, 2007; Rueda, Posner \& Rothbart, 2005). Por tanto, se observó un progreso en todos los tipos de inteligencia espacial, visual, musical-rítmica, natural, intrapersonal e interpersonal, siendo mayor la mejora en esta última y en la kinestésica corporal. De igual manera, se logró un desarrollo de la inteligencia lingüística (Cojocariu \& Butnaru, 2014).

La intervención con juego dramático sobre los sujetos excluidos posibilitó el desarrollo de su pensamiento abstracto y de su creatividad (Bodrova \& Leong, 1996; Ginsburg et al., 2007; Pellegrini \& Gustafson, 2005; Howard-Jones, Taylor \& Sutton, 2010), especialmente, en el aspecto semántico de esta última (Lillard et al., 2012).
Además, se reportó que el uso del arte dramático hace que los sujetos vulnerables y excluidos ganen confianza en sí mismos y disfruten mejor su vida, al usar un modelo de gestión de emociones más adecuado para comprender las intenciones y los deseos ajenos (González, 2015; Prendiville \& Toye, 2007; Fernández-Berrocal y Extremera, 2002; Guil y Navarro, 2005). Igualmente, los sujetos reportan que la experiencia los libra de prejuicios y les permite vivir el presente de manera dichosa y plena (Parada, 2013), en tanto es una práctica que favorece el reconocimiento y, por esta vía, la resignificación de la condición de vulnerabilidad o exclusión.

Por otra parte, los estudiantes en condición de exclusión y vulnerabilidad intervenidos con el uso del drama creativo reportaron en manuscritos de evaluación de la experiencia, que su pensamiento sobre el futuro había cambiado, ya que incluían igualdad de oportunidades para participar y, pensaron que su papel debía ser activo en la construcción de dicho futuro. Además, informaron que sus imágenes sobre el futuro tenían impacto en sus proyectos, así como en el significado de sus experiencias (Lehtonen, 2012).

En cuanto al uso del arte dramático en poblaciones institucionalizadas en centros de acogida, este favoreció la reducción de 
los síntomas hospitalarios como pasividad, indiferencia, apatía, hiperreacción a situaciones (irritabilidad, agitación) y aislamiento. Además, les proveyó mayor comunicación visual, expresiva y vocal; haciéndolos más participativos y generándoles sentimientos positivos (Foloştină et al., 2015).

Se resalta que el uso del arte dramático con jóvenes en condición de vulnerabilidad y exclusión propició la creación de nuevos sentimientos y pensamientos para reinventarse a sí mismos, a su cotidianidad, a sus espacios y tiempos, y a su propia vida y conflictos. Al mismo tiempo, hacer teatro les posibilitó sensibilizarse con el otro, para dejar de ser vulnerables y ganar expresividad y soltura, al hacer más potentes sus cuerpos como órganos de expresión (Faraco, 2009).

Las posibilidades que el teatro brinda a los jóvenes vulnerables y excluidos les permiten inventar nuevas formas de vida, diferentes a la violencia, e incluir el derecho a la formación estética y cultural (Zanella, 2007). Dicha formación les permite configurarse como sujetos integrales constituidos social e históricamente por racionalidad, afectividad y corporalidad, para romper, a partir de estas afirmaciones, con los sentidos e imágenes relacionados con la juventud y con las vidas que hasta ahora habían conocido. Es decir, los jóvenes vulnerables aceptan los desafíos de crear nuevas y más enriquecidas relaciones con los otros (Rocha et al., 2011).

Se anota que los grupos intervenidos no sólo mejoraron sus habilidades cognitivas y sociales, sino que comprendieron mejor los mensajes propuestos por los textos teatrales y aprendieron conceptos básicos referidos a dicho arte, como teatro, actor, escena, directo, música, luz, agrupación o montaje.

Respecto a los sujetos en condición de discapacidad que tienen la oportunidad de hacer teatro, se encontró que las audiencias reelaboran su concepción sobre la discapacidad mental. Esto se logra cuando el público puede ver que los sujetos diferentes y con limitaciones muestran muchas habilidades, que son personas con sentimientos, opiniones e ideas propias, y con capacidad para aprender, sorprendiéndose y alegrándose por ello, viéndolos menos extraños y amenazantes. Por ende, se amplían las oportunidades sociales para las personas con diversas discapacidades, quienes desarrollan de forma importante su autoestima, al tener la oportunidad de ser actores; esta ejercitación les permite demostrar sus capacidades sociales, de comunicación verbal y no verbal, de improvisación y de manejo de sentimientos como la frustración o la satisfacción (Prioli, Souza, Leme \& Mugnai, 2007).

Al hacer teatro, los sujetos en condición de discapacidad también aprendieron a valorar y calificar su trabajo y sus opiniones, haciendo uso de su autonomía y ciudadanía. Igualmente, se ha observado que los niños y adolescentes en condición de inmigración o de refugio, cuando participan en actividades artísticas como improvisaciones y dramatizaciones, mejoran sus promedios académicos y experimentan de forma rápida la transición a la nueva cultura, recuperando el dominio de sí mismos y superando sus traumas y pérdidas (Rousseau et al., 2014).

\section{Discusión}

口-

Los resultados muestran que es posible generar prácticas de libertad en los sujetos vulnerables y excluidos a través del teatro. Dichas prácticas permiten, a través de la re- 
flexión y de la creación de nuevas imágenes y lenguajes, construir y reconstruir las memorias para generar nuevos valores y nuevas identidades, es decir, nuevos sujetos, una nueva realidad y un mundo nuevo.

Los resultados también muestran que estas prácticas de libertad son generadas por el teatro en el nivel psicológico, al permitir la expansión de la personalidad del sujeto frágil y marginado, aumentando su empatía, su reconocimiento y valoración de sí mismo y de los otros, además de sus capacidades de negociación y de construcción de acuerdos. Así mismo, las prácticas de libertad se generan al concebir la creatividad y la imaginación como formas superiores de comunicación consigo mismo, con los demás y con el mundo que nos rodea; formas que permiten mejorar e impactar positivamente sobre el mundo. La generación de prácticas de libertad se evidencia cuando el sujeto marginado gana en autovalía y en afirmación de su identidad, al convertirse en una persona capaz de expresar y gestionar de manera adecuada sus emociones, eliminando sus repeticiones enfermizas, sus perturbaciones $\mathrm{y}$, en general, aquello que le hace daño, alcanzando de esa manera el equilibro en su dimensión afectiva y emocional.

Aunque son claros los resultados sobre los aspectos individuales, como la reconstrucción de las historias personales, el desarrollo de las habilidades comunicacionales, la gestión emocional y la autoestima; debe reconocerse que estos constituyen solo el resultado de prácticas de libertad. Por ello, sería importante que el teatro, a través de la creatividad y la imaginación, pudiese ser usado para generar prácticas de liberación, para construir un mundo satisfactorio y en paz, que comprenda a plenitud la vida y la libertad; que pueda generar prácticas como la reconstrucción de las historias no oficiales protagonizadas por los excluidos, la conformación de sentimientos sociales de envergadura, como la solidaridad y la compasión, y la generación de una participación activa y comprometida en los sujetos para acometer la resolución de los problemas de su comunidad.

Los resultados también muestran que los métodos usados por el arte dramático para intervenir las poblaciones vulnerables son diversos y variopintos. Entre los métodos sobresalen: el formato de taller, la incorporación del cuerpo y de los sentidos, el uso de la narración para la creación de historias y las dramatizaciones. Estos métodos se caracterizan por exigir la acción, la implicación y la inmersión de los sujetos en las actividades propuestas. Esta riqueza metodológica, además de posibilitar la reinserción de los excluidos y de permitirles nuevos comienzos, representa en sí misma un campo de posibilidades para ser usado en otros procesos de formación humana y académica. A pesar de esto, es importante anotar que hacen falta técnicas que se ocupen de la reconstrucción de las historias comunitarias de colectivos, pueblos y localidades que han sufrido la pérdida de su memoria histórica.

En referencia a las formas de investigación utilizadas en los estudios que se revisaron, aunque abarcan un gran espectro de enfoques cualitativos y cuantitativos, los resultados muestran que no enfatizan en la determinación del impacto social de las intervenciones teatrales ni en la identificación y caracterización de las acciones y los cambios sociales desprendidos de dichas intervenciones

Por último, los autores llaman la atención acerca de las omisiones que los docu- 
mentos presentan en torno a poblaciones que sufren otro tipo de exclusiones que son comunes en nuestras sociedades, y que también son fruto de las imposiciones de la economía neoliberal.

Las fuentes consultadas no tienen en cuenta la exclusión que produce la privación del derecho a la salud causada por la privatización creciente de los sistemas sanitarios, tanto en países desarrollados como en el tercer mundo; esta es una situación que se ha evidenciado de forma cruel con la pandemia. Las preguntas para realizar son: ¿el teatro puede ayudar a solventar esta exclusión?, ¿puede devolverles a los sujetos la autoridad y el poder sobre su propio cuerpo?, ¿puede hacerles valientes para reclamar lo que les corresponde por el hecho de ser ciudadanos derechohabientes en una democracia? Ante estas preguntas surgen varias posibilidades, desde el uso del teatro para promover la salud con diferentes prácticas y para la prevención de enfermedades, hasta la formación de los ciudadanos para defender y gestionar sus derechos a la salud, y para exigir prestaciones sanitarias dignas. También cabe peguntarse: ¿qué posibilidades tendría el teatro de ayudar a gestionar procesos para que las comunidades logren su independencia alimentaria, y que el hambre y la desnutrición dejen de ser un problema mayúsculo en muchas de nuestras comunidades?

Otra vulnerabilidad que no se tiene en cuenta es la carencia de justicia, que en países como Colombia puede llegar a cifras de hasta el 60\% (Departamento Nacional de Estadística -DANE- y Departamento Nacional de Planeación -DNP-, 2017). Al respecto, surgen inquietudes sobre las posibilidades que tendría el teatro para ayudar a que los sujetos puedan obtener justicia y reparación y, a su vez, que las sociedades tengan justicia social con los "otros", con las poblaciones afrodescendientes, indígenas, vulnerables y excluidas; para formar a las fuerzas armadas y de policía para que vean a los civiles como sujetos de derecho, así estén desarmados, carezcan de poder político o económico. Por último, surgen inquietudes sobre las posibilidades que tendría el teatro para transformar las identidades de aquellos poderosos que en las sociedades contemporáneas victimizan, excluyen, vulneran, violentan y estigmatizan.

\section{A MOdO DE CONCLUSIÓN}

De acuerdo con los hallazgos de esta revisión, el arte dramático, al ser una experiencia de carácter total en la cual se involucra el cuerpo, los sentidos, la mente y los sentimientos, puede constituirse en una pedagogía de sí (Barragán, 2019), es decir, en una herramienta para ayudar a los menos favorecidos a mejorar su auto imagen, así como sus capacidades comunicativas, sociales, cognitivas y sensitivas. Tal potencialidad, por extensión, es susceptible de ser em- pleada como un mecanismo de aprendizaje, empoderamiento y cualificación del comportamiento de cualquier población. Al estar centrado en el trabajo creativo del sujeto vulnerable y excluido, es decir, en el sí mismo, este se va afirmando por la vía de diversas ejercitaciones, actitudes, conocimientos, posturas, disciplina y control, como despliegues que no son impuestos desde el afuera sino desde sí mismo y que, por tanto, implican una acción constante del sujeto sobre sí. 
En este sentido, las poblaciones frágiles y marginadas, a través del arte dramático como terapia alternativa, van configurando subjetividades en las que demandan conducción de sí, al ejercitar gestos desde los que enuncian símbolos, a partir de los cuales se forma un lenguaje del cuerpo que siempre está reorganizándose. Esta conducción de sí como elemento subjetivo se refleja cuando en una escena se afirma la individualidad al expresar una pasión, a partir de los elementos como el gesto virtuoso, la actitud atenta o la expresión sublime. En las prácticas teatrales, el sí mismo se cultiva al desplegar una vivencia grupal donde se encuentra la cooperación y el espacio para la construcción de la sociedad. También se cultiva un lenguaje permeado por un mundo sensible en el que aprendemos sobre nuestro propio universo, a partir de la actuación de sentimientos, atravesados por la creatividad, la ética, la estética, la autonomía, la libertad, la objetividad, la subjetividad, las emociones, la imaginación y la intuición. Por tanto, las artes dramáticas impulsan una conducción de sí, un conocimiento de sí y un empoderamiento del sujeto, a partir de experiencias permanentes que refinan su ser.

De esta manera, la vivencia del arte dramático ayuda a la población vulnerable y excluida a avivar un pensamiento afirmativo y una vida activa, en tanto provee procesos que potencian su subjetivación, su sí. En estas prácticas se viabiliza el despliegue de líneas de fuerza que tensan y que hacen factible un distanciamiento de aquello que disciplina, controla, fija, aquieta, insensibiliza y genera temor en el sujeto. Este arte posibilita confrontar el poder que, como interiorización del afuera, cosifica y nubla al sujeto; estos son aspectos que no permiten percibir la belleza real del afuera, la cual requiere ser recordada y memorizada en el adentro (Deleuze, 2015), a partir del reconocimiento de lo sustantivo y sublime de ella y de la actuación con plenitud y sentido.

Así, las experiencias teatrales se constituyen en una terapia alternativa para contrarrestar problemáticas de sujetos vulnerables o excluidos a través de la creación de escenas por parte del sujeto porque los sujetos afirman su interioridad, acrecientan de forma singular su individualidad y se reinventan como personas. En otras palabras, los sujetos generan una producción de subjetivación que favorece una transformación de sí, que aumenta la creatividad estética y coadyuva a márgenes de libertad para el sujeto, con las que es factible la vivencia de una estética de la libertad. En esta vivencia se visibiliza la emancipación del ser, sus fuerzas y vigores vitales centrados en su sí y, por ende, su auténtica individualidad y existencia humana. Todo ello contribuye a la conformación de una estética de la libertad como ámbito donde el sujeto instaura otras verdades con las que da sentido a su vida y al mundo.

El arte dramático favorece que las poblaciones en situación de marginamiento se vean tal como son, porque su práctica demanda de una conexión con la interioridad, en la que se activa una constante revisión y análisis de significado, a partir de una aprehensión de la diversidad de pensamientos y acciones que en él se despliegan. Ello coadyuva a que dichas poblaciones sean lo que nunca fueron, servidoras de sí mismas, desde la disposición de experiencias, prácticas y saberes. Es decir, facilita que se plieguen en función de tener como foco la preocupación por ellas mismas y por el cultivo de lo estético y lo ético; de esta forma, se genera una elaboración y una transformación en 
función de que se conviertan en seres distintos para acceder a otras verdades, a la liberación espiritual y a la virtud (Foucault, 2002).

En este tipo de recuperación del poder confiscado a las personas en situación de vulnerabilidad y exclusión es en el que ubicamos las oportunidades y fortalezas que les brindan las artes dramáticas. Así, al haber potenciado la sensibilidad a partir de experiencias teatrales, a los sujetos les es posible no enfocarse en la marginación, en vencer al otro o en una lucha por la existencia, sino en ocuparse de sí mismos, sin dejar de reconocer la relevancia del otro, en la afirmación de sí.

Finalmente, como esta población está constituida por los excluidos y frágiles, para reducir sus desventajas, es necesario que el uso del teatro se considere como política pública por parte de los gobiernos locales, regionales y nacionales.

\section{Nota}

口

1. Este artículo es producto de la investigación: Historia presente de la docencia como práctica del decir verdad social y singularidades del decir en escuelas públicas del municipio de Medellín. Comité de Investigaciones -CODI- de la Universidad de Antioquia, acta 790. Proyecto desarrollado a partir de cooperación intrainstitucional, entre el grupo de investigación interuniversitario de Historia de la Práctica Pedagógica, categoría A1, Colciencias; el grupo de investigación Innovaciencia, categoría $\mathrm{C}$, Colciencias; y desde un trabajo interinstitucional con la Asociación Pequeño Teatro de Medellín

\section{REFERENCIAS}

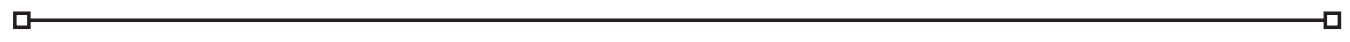

Alcántara, M. (2006). Arte y poder. Duererías, 7, 60-71. Recuperado de https://es.scribd.com/document/17937270/n7

Bakhtin, M. (1990). Author and hero in aesthetic activity. In M. Holquist y V. Liapunov (Ed.), Art and answerability (pp. 1-256). Austin: University of Texas Press.

Baracaldo, L. y Niño, S. (2015). El juego dramático como propuesta pedagógica para fortalecer la autoestima en los adolescentes de 15 a 18 años de edad en la fundación (trabajo inédito de pregrado). Corporación Universitaria Minuto de Dios, Colombia.

Barragán, B. (2019). Pedagogías de sí. La invención del maestro. En C. E. Noguera y D. A. Rubio (Eds.), Genealogías de la pedagogía (pp. 153-174). Bogotá: Universidad Pedagógica Nacional, Doctorado Interinstitucional en Educación.

Beare, D. \& Belliveau, G. (2008). Dialoguing scripted data. In S. Springgay, R. Irwin, C. Leggo y P. Gouzouasis (eds.), Being with A/r/tography (pp. 141-149). Rotterdam: Sense Publishers.

Beauregard, L. A., Bouffard, R. y Duclos, G. (2005). Autoestima: para quererse más y relacionarse mejor. Madrid: Narcea S.A. de Ediciones. 
Blair, C. \& Peters, R. (2007). Relating effortful control, executive function, and false belief understanding to emerging math and literacy ability in kindergarten. Child Development, 78(2), 647-663.

Boal, A. (2009). A Estética do Oprimido. Río de Janeiro: Garamond y Funarte MinC

Bodrova, E. \& Leong, D. (2007). Tools of the mind. The Vygotskian approach to early childhood education. Nueva Jersey: Pearson Education

Brooke, S. L. (2009). The use of the creative therapies with chemical dependency issues. Springfield, Illinois: Charles C. Thomas Publisher Ltd.

Butterwick, S., \& Selman, J. (2012). Embodied knowledge and decolonization: Walking with theater's powerful and risky pedagogy. New Directions for Adult and Continuing Education, 2012(134), 61-69. https://doi.org/10.1002/ace.20018

Chejov, A. (1999). Tío Vania. Alicante: Biblioteca Virtual Miguel de Cervantes. http://www.cervantesvirtual.com/obra-visor/tio-vania--0/html/ff0a16fc-82b1-11df-acc7-002185ce6064_1.htm\#1

Cojocariu, V.-M., \& Butnaru, T. (2014). Drama Techniques as Communication Techniques Involved in Building Multiple Intelligences at Lower-elementary Students. Procedia - Social and Behavioral Sciences, 128, 152-157. https://doi.org/10.1016/j.sbspro.2014.03.135

Copple, C. \& Bredekamp, S. (2009). Developmentally appropriate practice in early childhood programs serving children from birth through age 8. Washington: National Association for the Education of Young Children. https://www.naeyc.org/sites/default/files/globally-shared/downloads/ PDFs/resources/position-statements/PSDAP.pdf

Cordeiro, M. P., Scoponi, R. de S., Ferreira, S. L., \& Vieira, C. M. (2007). Deficiência e teatro: arte e conscientização. Psicologia: Ciência e Profissão, 27(1), 148-155. https://doi.org/10.1590/S141498932007000100012

Côrtes, M. (2014). Portas EntreAbertas: um relato etnográfico a partir de um fazer teatro com pessoas privadas de liberdade - para além do espetáculo. Revista Brasileira de Estudos da Presença, 4 (2), 351-376.

Costley, C., Elliot, G. \& Gibbs, P. (2010). Doing work based research: Approaches to enquiry for insider-researchers. London: SAGE Publications Ltd.

Crimmens, P. (2006). Drama therapy and storytelling in special education. London: Jessica Kinsley Publishers.

Dansky, J. L. (1980). Cognitive consequences of sociodramatic play and exploration training for economically disadvantaged preschoolers. Journal of Child Psychology and Psychiatry, 21(1), 47-58. https://doi.org/10.1111/j.1469-7610.1980.tb00015.x

Datoo, A. \& Chagani, Z. (2011). Street Theatre: Critical pedagogy for social studies education. Social Studies Research and Practice, 6(2), 21-30. https://ecommons.aku.edu/cgi/viewcontent. cgi?article $=1079 \&$ context $=$ pakistan_ied_pdck

Deleuze, Gilles. (2015). Foucault. Buenos Aires: Paidós 
Departamento Nacional de Estadística -DANE- y Departamento Nacional de Planeación -DNP- (14 de mayo de 2017). Seis de cada 10 que acuden a la justica se declaran insatisfechos. El tiempo, p. 1. https://www.eltiempo.com/justicia/servicios/cifras-de-insatisfaccion-con-el-sistema-de-justicia-en-colombia-87806

Dickinson, R. \& Neelands, J. (2006). Improve your primary school through drama. London: David Fulton Publishers.

Faraco, C. (2009). Linguagem e diálogo: as idéias lingüísticas do círculo de Bakhtin. Buenos Aires: Parabola Editorial.

Fernández-Berrocal, P. y Extremera Pacheco, N. (2002). La inteligencia emocional como una habilidad esencial en la escuela. Revista Iberoamericana de Educación, 29(1), 1-6. https://rieoei.org/ RIE/article/view/2869/3813

Fischer, H. (1982). L'historie de I'art est terminé. Paris: Editorial Balland. https://gallica.bnf.fr/ ark:/12148/bpt6k33329085.texteImage

Foloştină, R., Tudorache, L., Michel, T., Erzsébet, B., \& Duţă, N. (2015). Using Drama Therapy and Storytelling in Developing Social Competences in Adults with Intellectual Disabilities of Residential Centers. Procedia - Social and Behavioral Sciences, 186, 1268-1274. https://doi. org/10.1016/j.sbspro.2015.04.141

Foucault, M. (2001). Los anormales. México: Fondo de Cultura Económica.

Foucault, M. (2002). La hermenéutica del sujeto. México: Fondo de Cultura Económica.

Gardner, H. (1999). Mentes extraordinarias. Cuatro retratos para descubrir nuestra propia excepcionalidad. Barcelona: Kairos.

Gasparini, L., Bracco, J., Galeano, L. y Pistorio, M. (2018). Desigualdad en países en desarrollo: ¿Ajustando las expectativas? Argentina: Universidad de la Plata.

Ginsburg, K. R., The Committee on Communications \& The Committee on Psychosocial Aspects of Child and Family Health. (2007). The importance of play in promoting healthy child development and maintaining strong parent- child bonds. Pediatrics, 119(1), 182-191. Doi:10.1542/ peds.2006-2697

González, J. (2015). Dramatización y educación emocional. Revista de Investigación Educativa, 21, 98-119. https://cpue.uv.mx/index.php/cpue/article/view/1723

Grimson, A. (2014). Políticas para la justicia social. En A. Grimson (comp.). Culturas políticas y políticas culturales (pp. 9-14). Ciudad Autónoma de Buenos Aires: Fundación de Altos Estudios Sociales.

Guil, A. y Navarro, M. (Directores) (2005). Habilidades sociales en educación a través del juego dramático. Vídeo de prácticas [video File]. https://www.youtube.com/results? search_query=Habilidades + sociales + AND + juego + dram $\% C 3 \%$

Guner, H., \& Guner, H. N. (2012). Theatre for Education. Procedia-Social and Behavioral Sciences, 51,328-332. https://doi.org/10.1016/j.sbspro.2012.08.168 
Rich Harris, J. (1995). Where is the child's environment? A group socialization theory of development. Psychological Review, 102(3), 458-489. https://faculty.weber.edu/eamsel/Classes/ Child\%203000/Lectures/3\%20Childhood/SE\%20development/JudithHarris.html

Howard-Jones, P., Taylor, J., \& Sutton, L. (2002). The Effect of Play on the Creativity of Young Children During Subsequent Activity. Early Child Development and Care, 172(4), 323-328. https:// doi.org/10.1080/03004430212722

Karakelle, S. (2009). Enhancing fluent and flexible thinking through the creative drama process. Thinking Skills and Creativity, 4(2), 124-129. https://doi.org/10.1016/j.tsc.2009.05.002

Kemmis, S. (2007). Action research. In. M. Hammersley (Ed.), Educational research and evidence based practice (pp. 167-180). London: Sage.

Koudela, I.D. (1992). Jogos teatrais. São Paulo: Ed. Perspectiva.

Lehtonen, A. (2012). Future Thinking and Learning in Improvisation and a Collaborative Devised Theatre Project within Primary School Students. Procedia - Social and Behavioral Sciences, 45, 104-113. https://doi.org/10.1016/j.sbspro.2012.06.547

Lillard, A; Pinkham, A. y Smith, E. (2011). Pretend play and cognitive development. In U. Goswami (eds.), Handbook of cognitive development (pp. 285-311). London: Blackwell.

Lillard, A. S., Lerner, M. D., Hopkins, E. J., Dore, R. A., Smith, E. D. \& Palmquist, C. M. (2012). The impact of pretend play on children's development: A review of the evidence. Psychological Bulletin, 139(1), 1-34. https://doi.org/10.1037/a0029321

Massey, J. \& Koziol, S. (1978). Research Roundup: Research on creative dramatics. The English Journal, 67(2), 92-95.

Mesquita, P. (2012). Em busca de um teatro feminista: relatos e reflexões sobre o processo de criação do texto e espetáculo "Jardim de Joana" (trabajo de investigación de maestría). Universidade do Estado de Santa Catarina, Florianápolis, Brasil.

Motos, T. (1995). Teatro. Dinamización y educación plural. En G. Laferrière, A. Tordera y T. Motos (eds.), Los escenarios de fin de siglo: Teatro, tecnología y educación plural (pp.141-164). Valencia: Universidad Internacional Menéndez Pelayo.

Motos, T. (2010). Teatro Imagen: Expresión corporal y dramatización. Aula, (16), 49-73.

Motos Teruel, T. y Navarro Amorós, A. (2003). El papel de la dramatización en el curriculum. Articles, 29, 10-28. https://www.postgradoteatroeducacion.com/wp-content/uploads/2013/07/El-papel-de-la-dramatizaci $\% \mathrm{C} 3 \% \mathrm{~B} 3 n$-en-el-curriculum.-Por-Tom $\% \mathrm{C} 3 \% \mathrm{~A} 1$ s-Motos-y-Antoni-Navarro.-Revista-Articles-de-la-Ed.-Gra\%C3\%B3.pdf

Muncey, T. (2010). Creating Autoethnographies. Los Angeles: Sage Publications.

Navarro Solano, M. R. (2005). El valor pedagógico de la dramatización: su importancia en la formación inicial del Profesorado (tesis inédita de doctorado). Universidad de Sevilla, Sevilla, España. 
Navarro Solano, M. R. (2006). El valor pedagógico de la dramatización: su importancia en la formación inicial del profesorado. Creatividad y Sociedad, 9, 11-18. https://dialnet.unirioja.es/servlet/ articulo? codigo $=2312726$

Navarro Solano, M. R. (2007). Drama, creatividad y aprendizaje vivencial: Algunas aportaciones del drama a la educación emocional. Cuestiones Pedagógicas, 18, 161-172. https://idus.us.es/xmlui/ bitstream/handle/11441/12845/file_1.pdf? sequence $=1 \&$ isAllowed $=y$

Navarro Adelantado, V. (2002). El afán de jugar. Teoría y práctica de los juegos modernos. Barcelona: Publicaciones INDE.

Organización de Naciones Unidas -ONU- (2007). Declaración de las naciones unidas sobre los derechos de los pueblos indigenas. Bogotá: Imprenta Nacional de Colombia.

Parada, A. (2013). El Juego Dramático. Un ambiente creativo aplicado a la enseñanza formal de adolescentes (tesis inédita de doctorado). Universidad Autónoma de Madrid, Madrid, España.

Pellegrini, A. y Gustafson, K. (2005). Boys' and girls' uses of objects for exploration, play, and tools in early childhood. In A. Pellegrini \& P. Smith (Eds), The nature of play: Great apes and humans (pp. 113-135). New York: Guilford Press.

Prendiville, F. \& Toye, N. (2007). Speaking and listening through Drama 7 - 11. London: Sage.

Prioli Cordeiro, M., De Souza Scoponi, R., Leme Ferreira, S. y Mugnai Vieira, C. (2007). Deficiência e teatro: Arte e conscientização. Psicologia Ciência e Profissão, 27(1), 148-155. http://pepsic. bvsalud.org/scielo.php?script $=$ sci_arttext\&pid=S1414-98932007000100012

Rocha Furtado, J., Levitan, D., Piana Titon, A., Velarde Castillo, P. \& Vieira Zanella, A. (2011). Teatro sem vergonha: Jovens, oficinas estéticas e mudanças nas imagens de si mesmo. Psicologia: Ciência e Profissão, 31 (1), 66-79. https://www.redalyc.org/articulo.oa?id=282021809007

Rousseau, C., Beauregard, C., Daignault, K., Petrakos, H., Thombs, B. D., Steele, R., Vasiliadis, H. M., \& Hechtman, L. (2014). A cluster randomized-controlled trial of a classroom-based drama workshop program to improve mental health outcomes among immigrant and refugee youth in special classes. PLOS ONE, 9(8), 1-9. https://doi.org/10.1371/journal.pone.0104704

Rueda, M. R., Posner, M. I., \& Rothbart, M. K. (2005). The Development of Executive Attention: Contributions to the Emergence of Self-Regulation. Developmental Neuropsychology, 28(2), 573-594. https://doi.org/10.1207/s15326942dn2802_2

Pereira, B. R. (julho, 1999). O contexto social e a deficiência. Psicologia: Teoria e Prática, 1(1), 51-55. Universidade Presbiteriana Mackenzie. http://editorarevistas.mackenzie.br/index.php/ptp/ article/view/1141/838

Schechner, R. (1985). Between theater and anthropology. Filadelfia: University of Pennsylvania Press.

Sattler, J. (1992). The assessment of children: WISC-III and WPPSI-R supplement. San Diego: Sattler. 
Silverman, D. \& Marvasti, A. (2008). Doing qualitative research: A comprehensive guide. Los Ángeles: Sage Publications.

Souza Viera, M. (2012). As Contribuições da Pedagogia de François Delsarte para o Ensino da Dança Moderna. Revista Brasileira de Estudos da Presença, 2(2), 1-13.

Stagnitti, K., \& Unsworth, C. (2000). The Importance of Pretend Play in Child Development: An Occupational Therapy Perspective. British Journal of Occupational Therapy, 63(3), 121-127. https://doi.org/10.1177/030802260006300306

Tadeo, J. (2012). Integración de la memoria, recuerdo histórico y teatro en la educación en Colombia: Implicaciones pedagógicas y psicosociales. Psychología. Avances de la disciplina, 6(1), 13-20

Vandenberg, B. (1980). Play, problem solving, and creativity. New Directions for Child and Adolescent Development, 9, 49-68.

Wayman, S. (2009). Futures thinking, the ability to envision scenarios of a more desirable future. In A. Stibbe (Eds.), The handbook of sustainable literacy. Skills for a changing world (pp. 94-98). Devon, England: Green Books.

Winston, J. (2005). Entre lo estético y lo ético: analizar la tensión en el corazón del teatro en la educación. Revista de Educación Moral, 34(3), 309-323.

Wyver, S. R., \& Spence, S. H. (1999). Play and Divergent Problem Solving: Evidence Supporting a Reciprocal Relationship. Early Education \& Development, 10(4), 419-444. https://doi. org/10.1207/s15566935eed1004_1

Zanella, A. V. (2007). Educación estética y actividad creadora: herramientas para el desarrollo humano. Universitas Psychologica, 6(3), 483-492. 